\title{
Comensalidad en el contexto fúnebre al sur de los andes ecuatorianos
}

\section{Comensality in the funeral context south of the ecuadorian andes}

\section{Comensalidade no contexto fúnebre do sul dos andes equadores}

\author{
Elsa Rosario Sinchi Lojano \\ Universidad Complutense de Madrid \\ E-mail: esinchi@ucm.es
}

\section{Alberto de Campo Tejedor \\ Universidad Pablo de Olavide \\ E-mail: acamtej@upo.es}

\section{Resumen}

La influencia del cristianismo, los avances científicos en el campo de la medicina y la modernidad han incidido, profundamente, en la forma en que las sociedades andinas enfrentan la muerte. Sin embargo, aun en sus formas actuales, las prácticas mortuorias articulan complejas interrelaciones entre los participantes. El compartir de comida y bebida es el eje primordial.

Comer y beber son acciones inherentes al ser humano, tienen un valor especial y vital a nivel fisiológico y también a nivel social debido a tiene la capacidad de generar amplias connotaciones simbólicas y afectivas (Contreras, 1993). El segundo nivel ocupa el interés del presente trabajo. En él se analiza el impacto y las funciones de la comensalidad en el 
contexto fúnebre de núcleos rurales. Las reflexiones aquí expuestas derivan de las experiencias del trabajo etnográfico realizado entre los años 2016-2018 en las parroquias rurales Baños y Sinincay, ubicadas al sur de los Andes del Ecuador (Cuenca-Azuay). Estas comprensiones situadas se sustentan en una serie de experiencias (de observaciones, conversaciones, inferencias e interpretaciones) que dan cuenta de la formas de habitar e imaginar, de hacer y de significar el mundo fúnebre.

\section{Abstract}

The influence of Christianity, scientific advances in the field of medicine and modernity have profoundly affected the way Andean societies face death. However, even in their current forms, mortuary practices articulate complex interrelationships between participants. Food and drink sharing is the main focus.

Eating and drinking are actions inherent to the human being, they have a special and vital value at the physiological level and also on a social level because it has the ability to generate extensive symbolic and affective connotations (Contreras, 1993). The second level is of interest to this work. It analyses the impact and functions of dinerity in the funeral context of rural centres. The reflections set out here derive from the experiences of ethnographic work carried out between the years 2016-2018 in the rural parishes Baños and Sinincay, located south of the Andes of Ecuador (Cuenca-Azuay). These understandings are based on a series of experiences (of observations, conversations, inferences and interpretations) that give account of the way of living and imagining, of making and of meaning the funeral world.

\section{Resumo}

A influência do cristianismo, os avanços científicos no campo da medicina e a modernidade influenciaram profundamente a maneira como as sociedades andinas enfrentam a morte. No entanto, mesmo em suas 
formas atuais, as práticas mortuárias articulam inter-relações complexas entre os participantes. O compartilhamento de alimentos e bebidas é o eixo principal.

Comer e beber são ações inerentes ao ser humano, possuem um valor especial e vital no nível fisiológico e também no nível social devido à capacidade de gerar amplas conotações simbólicas e afetivas (Contreras, 1993). O segundo nível ocupa o interesse do presente trabalho. Analisa o impacto e as funções da comensalidade no contexto fúnebre das áreas rurais. As reflexões aqui apresentadas derivam das experiências do trabalho etnográfico realizado entre os anos de 2016 a 2018 nas paróquias rurais de Baños e Sinincay, localizadas no sul dos Andes do Equador (Cuenca-Azuay). Esses entendimentos situados são sustentados por uma série de experiências (de observações, conversas, inferências e interpretações) que explicam os modos de habitar e imaginar, de fazer e de significar o mundo do funeral.

\section{Introducción}

La antropología ha explorado diferentes perspectivas a lo largo del tiempo para dar cuenta de las representaciones acerca de la relación ente la vida y la muerte (Durkheim, 1897 Hertz, 1990; Thomas, 1993; Malinowski, 1994). Este recorrido nos permite comprender hoy en día a la muerte como un proceso biológico y social, atravesado por rasgos universales de acuerdo a las variables culturales, y no universales conforme a lo que diversas culturas pueden producir al momento de enfrentar la muerte. 


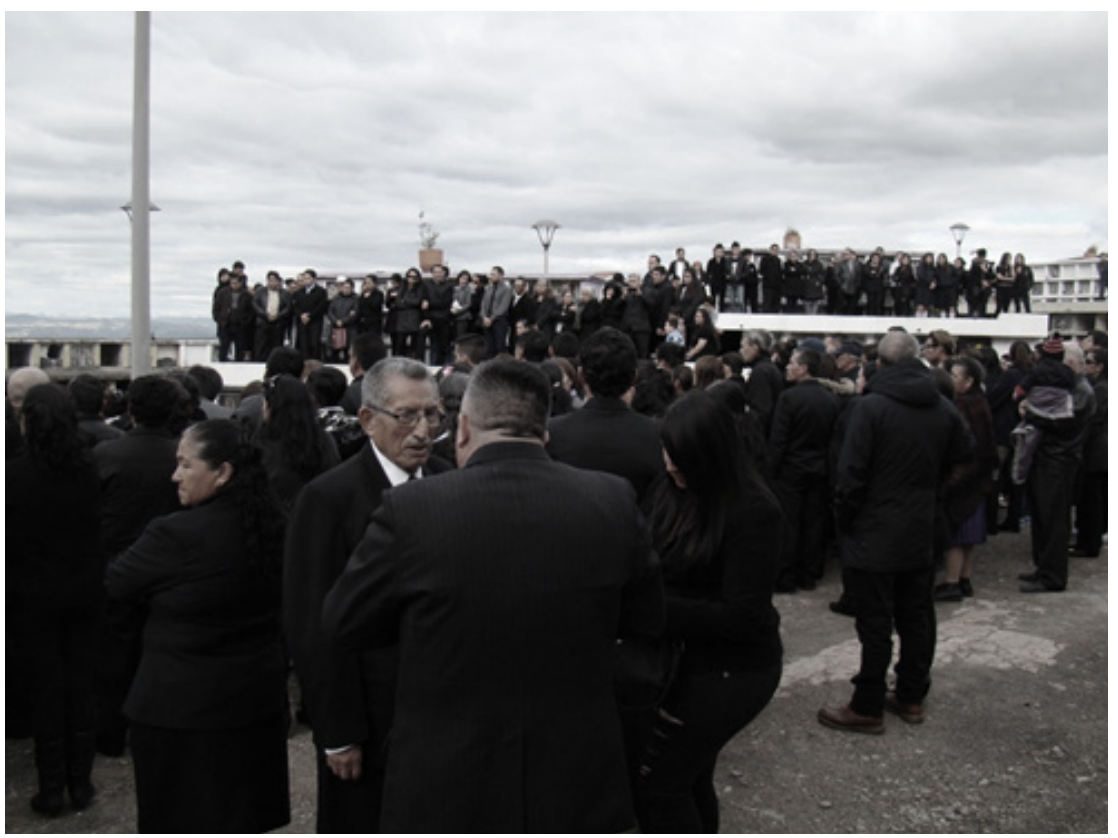

Figura 1: El Entierro. Baños, 2017

Como hecho social trascendente, la muerte precisa emociones que son canalizadas dentro de una serie de códigos socioculturales que enmarcan la práctica funeraria lo que se conoce como ritos; acciones encaminadas a favorecer el cambio de un estado hacia otro (Gennep, 2008). En este proceso de reestructuración la comida y la bebida juegan un rol fundamental.

Comer y beber tiene un valor especial y vital en la dieta de los seres humanos. Pero sus funciones no son exclusivamente fisiológicas, sino también de orden social, político y ritual. (Appadurai 1986). Por lo tanto, más allá de la nutrición, al hecho de comer y beber se lo entiende como "un fenómeno social, psicológico, económico, simbólico, religioso, cultural en el más amplio sentido del término" (Contreras, 1995 p. 10). 
En la geografía andina, los pueblos indígenas y campesinos tejen sus relaciones emocionales y afectivas en base a la comida y a la bebida (Weismantel, 1998; Mintz 1985; Meiggs, 1997; Ferraro 2004). Por ejemplo, en fiestas, rituales, mingas y aun en la vida cotidiana andina compartir la comida y la bebida tiene la cualidad de unir, congregar y propiciar sentimientos de parentesco y de colectividad (Carsten, 1995, p. 224).

Las referencias tempranas de los Andes describen al hecho de comer y beber en abundancia como características propias y necesarias de la práctica fúnebre en los pueblos andinos. Pablo J. de Arrriaga indicaba al respecto:

[...] Diez días después de la muerte del difunto se junta todo el ayllo y parentela y llevan al pariente más cercano a la fuete o corriente del río que tiene señalado y le zambullen tres veces y lavan toda la ropa que era del difunto, y luego se hace una merienda, y el primero bocado que mascan lo echan fuera de la boca; acabada la borrachera se vuelven a la casa y barren el aposento del difunto y echan la basura fuera, cantando los hechiceros, y esperan cantando y bebiendo toda la noche siguiente al ánima del difunto, que dicen que ha de venir a comer y a beber $[\ldots](1621$, p. 66).

No obstante, desde la época colonial son conocidos los intentos de supresión de tales "excesos" por medio de persecuciones y prohibiciones cristianas (siendo el paradigma la extirpación de idolatrías).. Y si bien en la república son más conocidos los métodos de asimilación, con el fin de desterrar la "barbarie", la idea de la erradicación de los "excesos" persiste hasta nuestros días. A esto se suma el avance del campo de la medicina y la modernidad, que, bajo la consideración de la medicalización y el ocultamiento de la muerte, han generado nuevas formas de pensarla y sentirla.

En las grandes urbes es verdad que se evidencia cierta "moderación" en las prácticas fúnebres. Sin embargo, en sus poblados periféricos, el 
pasado y el presente se conjugan y crean dinámicas propias frente a la muerte. Y precisamente, uno de los ejes de articulación social que pervive en el tiempo es el hecho de comer y beber juntos.

Bajo estas consideraciones, el presente artículo tiene como objetivo analizar el impacto y las funciones que tiene la comensalidad en la práctica fúnebre rural. El contexto de estudio son las prácticas fúnebres domiciliares en las parroquias rurales Baños y Sinincay, ubicadas al sur de los andes ecuatorianos (Cuenca-Azuay). Las reflexiones que aquí se exponen buscan intercalar narraciones que tienen como fin expresar la espiritualidad andina viva a través de la comensalidad.

La metodología de trabajo se fundamentó principalmente en la etnografía, desde donde se ha ejecutado un proceso reflexivo y consciente, sustentado en observaciones, conversaciones, inferencias e interpretaciones (Guber, 2001; Restrepo, 2018), destinado a responder la importancia de la comensalidad en el contexto fúnebre rural. Las descripciones sobre las relaciones entre prácticas y significados particulares de estos contextos situados dan cuenta de la forma de habitar e imaginar, de hacer y significar la muerte, y por ende la vida.

La revisión de distintas contribuciones contemporáneas desde la etnografía andina (Duviols 1973; 158, Valcárcel 1980; 81, Cachiguano 2001; Emilia Ferraro 2004; 193), dan cuenta cómo en distintos momentos de la vida, las sociedades andinas tejen relaciones de reciprocidad a través de los alimentos. Pero estos aportes, si bien nos resultan valiosos para comprender los mecanismos de cooperación andina, no se enfocan en el contexto fúnebre. Otras etnografías centradas en las prácticas mortuorias de la sierra ecuatoriana (Rivet, 1910; Karsten, 1930; Hartman y Oberem, 1984; Brownrigg, 1971 y 1989, Ordoñez, 2004) resultan significativas debido a que entre sus descripciones consta el rol de la comida y la bebida en el ritual mortuorio. Al respecto, Brownrigg (1971) detalla que para los habitantes de Monjas de Quingeo (Azuay) la comida era concebida como un don de los vivos hacia los difuntos en espera de una reciprocidad que se vería reflejada en la productividad satisfactoria de 
los campos. La ofrenda de comida servía en este caso como un canal de comunicación entre estos dos mundos, el de los vivos y de los muertos. Karsten (1930) por su parte, describe la asociación entre las libaciones y los alimentos en el ritual mortuorio, y resalta el sacrificio de animales (corderos, cerdos, gallinas y cuyes) para el convite con los allegados. Hartmann y Oberem (1984) registran en el Sigsig-Azuay una comida especial del velorio llamada Auquin. De igual manera, Brownrigg (1989) registra en Monjas la comida del entierro llamada Ayaaparic, compuesta por cuy, papas y un litro de trago, que era ofrendada a los cuatro hombres que cargaban el ataúd del difunto después de las tres noches del velorio.

Hoy en día hablamos de cambios y trasformaciones en las prácticas mortuorias, pero también son evidentes las continuidades. Baños en el contexto rural resalta en el tiempo por la pirotecnia, las bandas de pueblo (música), las expresiones de espiritualidad en torno a la Virgen de Guadalupe (de trascendencia regional), la variedad gastronómica, las aguas termales, las artesanías y una rica tradición oral. Sinincay, por su parte, es también reconocida por su amplia tradición en la producción ladrillera. En estas parroquias la alimentación es crucial en distintos momentos sociales, entre ellos en la muerte, y dependiendo del momento del ritual: velación, entierro o el cinco, la alimentación alcanza distintas formas y dimensiones. Este artículo se ocupa de los dos primero momentos.

\section{Comensalidad en el ritual fúnebre}

Dentro de las múltiples facetas de la alimentación, los rituales de comensalidad, en tanto rituales de interacción, cubren toda la amplia área de los ritos interpersonales, se basan en el respeto entre los individuos, facilitan el contacto y las respectivas fases situacionales. La presencia constante de la alimentación en los ritos de paso hace considerar que su compartir sea un espacio ideal para la representación. En mesas festivas ceremoniales hay tantos niveles de identificación simbólica de atenuación 
de los conflictos presentes en la comunidad. La comida consagra, fortifica los lazos creados por las relaciones familiares, vecinales y los creados por el trabajo, reforzando la solidaridad, la amistad y la convivencia.

Desde el punto funcionalista en la comida ceremonial todos los participantes tienen la oportunidad de ver sus comportamientos entre sí, y comprobar, hasta qué punto los diferentes autores cumplen sus papeles sociales (Geertz 1997).

En los funerales la comida es un símbolo de unión entre los superivientes (Van Gennep, 2008) y compartirla se sustenta en un sentido de cooperación mutua -don y reciprocidad. Estas acciones, enmarcadas en el rito de la comensalidad fúnebre, involucran una cierta comunión de costumbres, valores y códigos, en otras palabras, comprender un mismo lenguaje simbólico. Aspectos que son objeto de descripción y reflexión de los siguientes apartados.

\subsection{El café y las galletas}

El velorio reúne a todos quienes conocieron alguna vez del difunto. Al ser el primer evento público de la muerte, los dolientes tienen un total esmero en las atenciones a los asistentes. Asimismo, los asistentes intentan hacer notar su presencia ante los dolientes a través de la ofrenda de bienes, de servicios y de alimentos. Los primeros asistentes: vecinos, amigos, familiares, llegan a la casa de los dolientes y se ofrecen a ayudar en distintas actividades: limpiar la casa, organizar rezos, trasladan mesas, sillas y demás cosas que hagan falta. Mientras reciben la ayuda, los dolientes preparan grandes ollas de café y agua aromática, y se abastecen de las galletas necesarias para ofrecer a los asistentes. La preparación de estos alimentos requiere de poco esfuerzo y se caracteriza por la sencillez de su presentación: un vaso de café y una fuente de galletas de sal.

Los asistentes que llegan a velar al difunto traen entre sus manos "pequeñas ayudas" de alimentos: pan, galletas, granos secos, fundas 
de fideos, atados de frescos ${ }^{1}$, animales vivos, zhumir $^{2}$ y gasesosa, para ofrecer a los dolientes, algunos de estos alimentos son compartidos en el acto, mientras que otros pueden quedar como reserva para los ritos posteriores (entierro y el cinco), lo cierto es que todos los dones - en alimentos- que los deudos reciben son compartidos en los distintos momentos del ritual fúnebre.

La bebida es otra característica de las comidas rituales fúnebres. Esta propicia la charla, la comunicación y el carácter festivo y comunitario en el funeral. Al igual que los alimentos, el aguardiente forma parte de los dones que los amigos y vecinos ofrendan a los deudos. El aguardiente que reciben los deudos es transformado en una bebida conocida como canelazo ${ }^{3}$, esta es convidada a todos los asistentes, pero quienes consumen en mayor cantidad son los hombres. Durante el día el consumo de aguardiente es esporádico, mientras que en la noche se bebe en más abundancia, a tal punto que no es extraño ver que alguien se haya excedido en su consumo y se convierta en el narrador oficial de los chistes, secundado por otros hombres quienes también han alcanzado cierto grado de embriaguez. Acciones que rompen con la formalidad de un velatorio convencional, en donde la tristeza y el dolor son característicos.

La comida del velorio se caracteriza por ser totalmente incluyente, "hay café y galletas para todos". Los dolientes consideran como un acto vergonzoso y posible causal de "malentendidos" el hecho de que algún asistente abandone la velación sin haber tomado café, ya que implica ausencia de hospitalidad y reciprocidad a la asistencia vecinal, lo que puede generar una deuda que solo tendrá fin el momento que el doliente pueda extender las disculpas del caso:

1. Compuesto de varias plantas aromáticas: hierba luisa, ataco, cola de caballo, cedrón, claveles. A esta infusión se le añade limón.

2. Bebida alcohólica tradicional del Azuay, elaborada en base a la caña de azúcar.

3. Bebida que se sirve caliente, resultado de la mezcla de aguardiente de caña con agua caliente de canela y azúcar. También alterna la mezcla con naranjilla o ataco 
¡Cómo no te vas a fijar! [reclamaba la viuda a una de sus hijas] ¿En dónde estaba mi cabeza que no le vi que se fue? ¿Y ahora? Ellas vienen porque tiene buena voluntad ipor eso nos acompañan!, no están obligadas, pero nosotros ¡nada, ni un vaso de agua! ¿Cómo ha de pasar esto? Ojalá entiendan que es por el momento duro que estamos pasando, ni cuenta me he dado que se han ido ¿porque no me ayudas?, tienes que estar pendiente. (Mujer de 54 años, Sinincay: 2018).

El don ofrendado, especialmente de comida, tiene por objetivo el establecimiento de lazos sociales que se constituyen en una red de obligaciones entre individuos y grupos, volviéndose más obligatoria entre parientes, estos últimos necesitan de un sistema mutuo de endeudamiento y dependencias para sostenerse (Ver Mauss 1979; Sahlins 1977b).

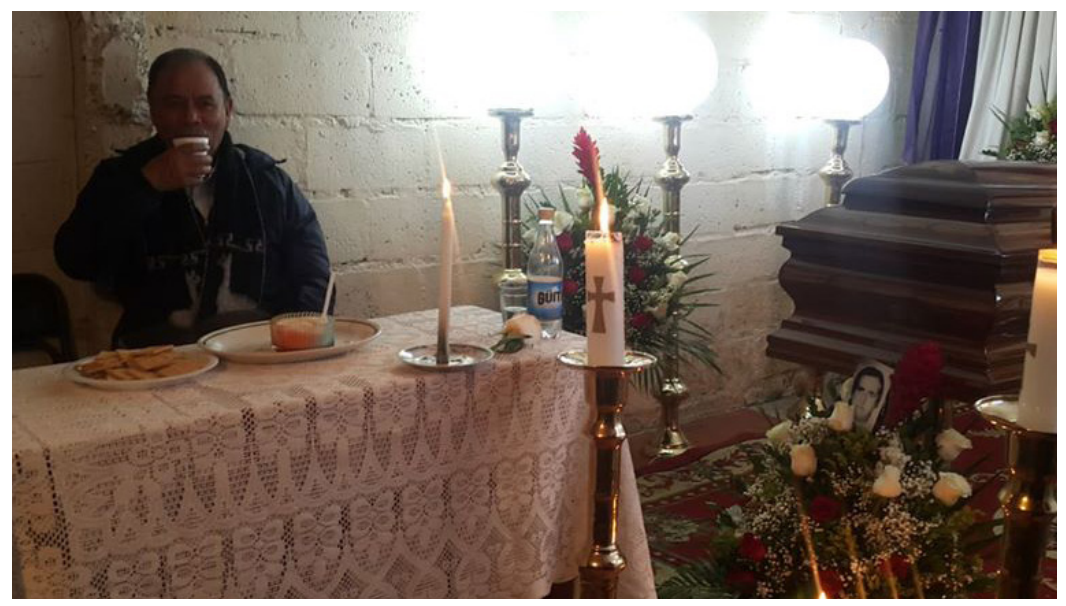

Figura 2. Sacerdote después de la eucaristía domiciliar. Baños, 2018

Las acciones de cooperación que tienen lugar en el velorio revelan un profundo sentido del "deber", entendido como una acción positiva que permite al individuo y a la comunidad superar una determinada problemática (Ferraro, 2004). Bien pueden ser entendidas como 
"prestamos" - de dinero, comida, servicios o bienes- que deberán ser correspondidos a futuro. Implican una negociación en el tiempo:

Yo les prometí a mis vecinos, los Ordoñez, que así como me ayudaron en la muerte de mi papasito. Cuando ellos pasen por un dolor igual, o una necesidad cualquiera, yo seré el primero en estar allí. Es mi forma de pago, es mi modo de ver la vida. Yo he aprendido a que uno tiene que ser agradecido hasta para que Dios le ayude. Los vecinos me ayudaron en todo de la velación, ha traído las sillas, las mesas, han barrido el cuarto, han traídos lo montes para hacer agüita, han hecho casi todo antes que empiece a llegar la gente. Por eso yo sé que tengo algo pendiente con ellos. (Hombre de 56 años, Baños: 2018).

En esta fase los alimentos entran en la cadena del don y la reciprocidad, involucran relaciones sociales a corto y largo plazo y revela dimensiones vitales y connotaciones profundas relacionadas con una estrategia de producción y reproducción del orden social y cósmico. El temor a la sanción, implicado en el deber de devolver, hace que los dolientes prestan total atención a la devolución de las colaboraciones prestadas. El no prestar atención a los contradones puede desencadenar una serie de hechos negativos. Si los deudos fallan en sus responsabilidades con la comunidad (más todavía con sus familiares) quedan expuestos a la muerte social. En este sentido el café, las galletas y demás alimentos presentes en esta etapa, además de ser alimentos portadores de energía, representan solidaridad y hospitalidad.

\subsection{El banquete fúnebre}

Como si se tratara de los preparativos de una comilona festiva, la preparación del banquete que se ofrecerá después del entierro es también un evento extraordinario. La preparación de banquete inicia con el sacrifico animal. De manera paradójica, desde la muerte del animal toma sentido la regeneración de la vida.

La selección, la preparación y el consumo del banquete fúnebre, está 
condicionado por "gramáticas culinarias" que dan lugar a una expresión alimentaria particular (Fischler, 1979, Mintz, 2003). La carne, los granos secos, el arroz y las papas son los alimentos principales del banquete fúnebre. Y si bien la carne es un alimento aprobado para esta ocasión "extraordinaria", no todo tipo de carne animal es apta para el consumo dentro del contexto fúnebre. Por ejemplo, en la parroquia Baños, el cuy el cerdo y la chicha ${ }^{4}$ son alimentos relacionados con contextos festivos como matrimonios y bautizos, pero no con la muerte. Don Ángel, de 61 años de edad y don Eliseo de 80 años de edad afirmaban no recordar el consumo de estos alimentos en un funeral. La tradición, dicen, es comer la res y las gallinas. Mientras que en Sinincay estos mismos alimentos tienen gran aceptación dentro del contexto fúnebre y su uso depende de las condiciones socioeconómicas de los dolientes.

Si bien la tradición hereda alimentos inscritos culturalmente dentro de una cocina, además de transferir ingredientes, corpus culinario, técnicas de cocción y de conservación de los alimentos y representaciones culturales asociadas (Contreras, 1993), las propias dinámicas culturales abren la posibilidad de cambio de alimentos aptos para ser consumidos biológica y culturalmente.

Así, en las familias campesinas, y más en aquellas que poseen cierto prestigio social (asociado a priostazgo o cargos de representación comunitaria), el sacrificio de la res constituye algo excepcional, es un don importante asociado a actos festivos y rituales, en el sentido de que la familia ofrece algo valioso. Las gallinas (y pollos) están asociados a contextos familiares comunes. De allí que los alimentos no pueden ser considerados simples portadores de energía y de nutrimentos, sino provisiones colmadas de significados conferidos por una población (Mintz, 2003): riqueza, poder, prestigio, pureza, etnicidad por mencionar algunos.

4. Bebida que deriva, principalmente, de la fermentación no destilada de maíz. 
Los preparativos del banquete comienzan un día antes del entierro. Los deudos acostumbran a realizar una reunión familiar un día antes de entierro para decidir qué alimentos preparar para el banquete ritual. En una familia con una situación económica buena la comida es abundante, se sirve más de dos platos de comida: uno de caldo, otro de arroz con carne, otro de papas doradas, otro de locro de algún grano. Cuando la condición socioeconómica es media o baja, la comida es modesta: caldo y arroz con carne o a su vez solo el segundo plato.

En la víspera del entierro se adelanta el sacrificio de la res, de esta actividad se encargan los hombres adultos y ancianos con cierta experiencia. Mientras los hombres tienen un papel protagónico en el sacrifico del gran animal, las mujeres destacan como líderes irrefutables en la preparación del banquete. Pese a que su actuación, en gran parte es por separado, sin embargo, siempre entre los grupos -hombres y mujeres- comparten picardías: "¡Hay! este hueso duro, igualito al de la que sabemos", decía uno de los cortadores de la carne, a lo que reaccionaba una de las mujeres: "siquiera tiene a alguien a quien tocarle el hueso". Otro de los cortadores, su sumaba a las bromas diciendo: "sino que se toque solo el hueso, eso es más complicado", el bando de las mujeres, en respuesta, ríe a carcajadas.

El día del entierro, la cocina y el fogón de leña son tomados por un grupo de mujeres, en su mayoría, consanguíneas entre ellas y con los dolientes (nueras, cuñadas, sobrinas, hermanas). Todas muestran apuro por lograr a tiempo la preparación de la comida. La mujer más adulta dirige la preparación y divide las actividades para cada ayudante, y prevé la hora en la que todo estará listo. Prenden el fogón y sobre este colocan ollas grandes y repletas de agua. Mientras el fuego hace lo suyo, ellas hacen otras actividades en la cocina: trocean bien la carne, preparan los condimentos, escogen los granos de arroz y lo lavan, pican las finas hierbas (cebollín, perejil y cilantro), preparan el ají. La mujer que dirige la preparación pasea constantemente entre la cocina y fogón, vigilante a las novedades que pudiesen darse mientras hacen una y otra actividad. Al 
hervir las ollas, la guiadora empieza a colocar en estas los ingredientes; en la una el espinazo de la res y más tarde el fideo (para el caldo), en la otra el arroz y en la otra la carne troceada (para el bistec), en otra las papas y añaden en cada una las especerías necesarias. La cocción de los alimentos tarda entre dos a tres horas.

Pese al hecho de la muerte, la atmósfera de la cocina es alegre, con risas, conversaciones y complicidad. Cada cocinera busca entre su memoria anécdotas para compartirlas con sus compañeras. Una de ellas relataba: "me acuerdo cuando recién estaba aprendiendo a cocinar y he puesto ají en vez de pimiento, la comida estaba picante, pero calladitos comieron". Otra decía: "eso no es nada, una vez yo le di a mi esposo y a mis hijos caldo de estropajo, era caldo de pollo y cuando veo el estropajo me puse pálida, pero así le di de comer". Otra comentaba: "Yo sí les he hecho barbaridades, la peor fue cuando los porotos cocinados se me cayeron en el balde de los desperdicios, yo me dije ¡no voy a desperdiciar tanto!, les lavé y así les di”. De repente, de las experiencias en la cocina, pasan a los ex-novios y a las parejas actuales: "El antiguo guapo, lleno de vida, grande, yo y mis malas decisiones, escojo al más patojo, al más flaco, al más zhunzhito ${ }^{5 ",}$ las risas son escandalosas, las experiencias continúan "Yo en cambio por escoger al dicho guapo ahora no puedo ni pegar los ojos, hasta ver ya está de risueño por una lado y por el otro". Había otras conversaciones, son tan íntimas que ni la pared tenía acceso a ellas. Es evidente que preparar los alimentos constituye un espacio de autonomía relativa para las mujeres, donde cierto grado de elección es posible.

Así, la cocina se muestra como el verdadero corazón de cualquier casa del área rural; allí las conversaciones más íntimas tienen lugar, en ella se festeja y en ella se llora. Conjuga la presencia del hombre y la mujer en el proceso de producción y reproducción del orden social y de la vida familiar.

5. Expresión con la que se califica a una persona lenta, cabizbaja. 


\subsection{Comer y beber juntos.}

En la mayoría de las sociedades, comer es esencialmente una actividad social. No es una casualidad que la mayoría de las ocasiones sociales y religiosas que marcan los ciclos vitales de los individuos y comunidades estén acompañadas de comidas festivas o ceremoniales. El estar juntos, el encuentro regularizado y pautado respecto al proceso de alimentación, permite superar el nivel instintivo y fisiológico de satisfacer el hambre, para convertirse en un proceso socializador que supera la significación personal (Mead, 1951; Simmel, 1986).

Compartir la comida en el funeral comulga y fortifica las relaciones sociales entre los comensales y les permite a los dolientes sentirse acompañados y apreciados por los vecinos y amigos del lugar.

"el abrazo solidario y que compartan con uno es medicina, que se interesen como murió mi madre, que me pregunten cómo estoy, que lloren conmigo, eso ayuda a sanar mi alma. Uno se desahoga. Eso es lo que uno valora y lo que le da fuerzas, le da valentía. En esos momentos difíciles uno se da cuenta quienes en verdad le estiman. Y ahora todo eso ¿cómo se gradece? ¡Con la comidita! que se vayan siquiera bien comidos". (Hombre de 50 años, Baños, 2018).

La comida que se ofrenda a los invitados se convierte en el mecanismo esencial para la continuación social y material del grupo, pero además les permite a los dolientes elevar un homenaje al difunto y por su intermedio darle paz a su ser querido en el más halla y alcanzar -los dolientes- la tranquilidad terrenal.

"Por más humilde que sea el plato de comida es necesario, sirve para agradecer a los vecinos y amigos y para que el muertito vea que no está solo, que hay una familia que le quiere... que siempre le tendrá presente...sino se hace la comida los difuntitos se enojan...va a decir ¿para qué he trabajado tanto mientras vivía si ni 
siquiera despedirme bien pueden? Allí es cuando se complica, el almita viene a estar paseándose por acá, pero si se le despide con todas las honras: la misita, la comida ¿qué va a reclamar? ¡Nada! Esa es la ley de la vida. (Mujer de 45 años, 2017).

Pero el aspecto operacional del símbolo es también excluyente: distingue a los muertos de los vivos y marca la solidaridad entre estos últimos, excluye a los no elegidos al banquete ritual, estructura jerarquías dentro de los comensales, discrimina a los dolientes de los demás participantes del ritual, al simbolizar su nueva personalidad social, y establece fronteras más precisas (Goody 1984; Haaland 2007).

En Baños, la invitación selectiva al banquete que hacen los deudos después de que la fosa del difunto se haya sellado, es un claro ejemplo de que la comensalidad es también excluyente. Como un agradecimiento general los dolientes ofrendan a los asistentes adultos un vaso de gaseosa y una copa de aguardiente puro.

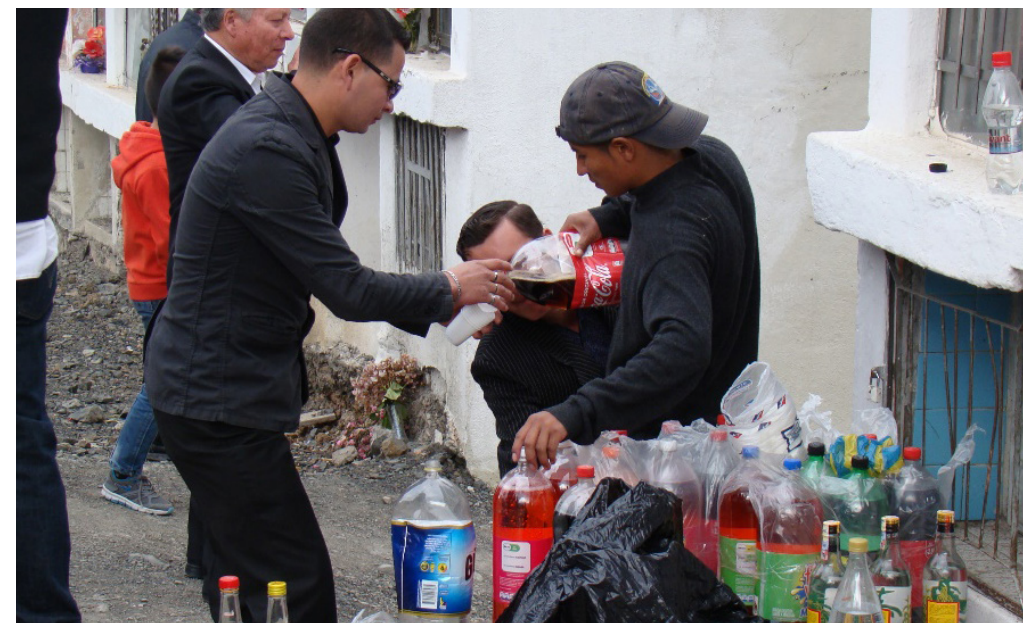

Figura 3. El aguardiente como ofrenda de agradecimiento. Baños, 2017 
Sin embargo, la invitación a participar del banquete lo hacen selectivamente: familiares directos, amigos cercanos y personas de prestigio en la localidad. De cierto modo se trata de un "listado" acordado entre los familiares antes de salir al entierro: "A todos los tíos, a los primos, a los compadres, a ellos primerito les dicen, no se descuidarán de ellos. Así como ellos han estado tan pendiente de nosotros", especificaba una doliente antes de ir al cementerio. Otra doliente les indicaba a sus hijos como hacer la invitación: "Ustedes vean más o menos a quién le invitan; bonito se acercan al oído y le dicen que acompañe un ratito a la casa, adentro en el cementerio les dicen o en la puerta, no importa que le digan dos veces, mejor, porque salido de allí ya es difícil". En Sinincay, la invitación al banquete fúnebre se la hace a través de un micrófono en el cementerio. Si bien la invitación no es tan personalizada con el caso de Baños, sin embrago no asisten todas las personas que están en el cementerio, lo toman como invitación directa los familiares, amigos y vecinos más allegados.

Por otra parte, si bien la gran mayoría participantes del banquete reciben la misma cantidad de comida, los cargadores del ataúd tienen una jerarquía distinta. "A los que cargaron el ataúd daranles bastante comidita, no vaya a ser que les vaya [el difunto] jalando, que falte para nosotros no importa, pero ellos que se vayan satisfechos y protegidos", decía uno de los hijos del difunto mientras esperaba que le entreguen nuevos platos de comida para servir a los invitados. A diferencia de los demás participantes, los cargadores del ataúd habían realizado una acción los había agotado física y psicológicamente. Don Manuel de 45 años (Sinincay) y la Señora Magdalena de 63 años (Baños) afirman que cargar el ataúd es "pesado", no solo en cuestión de cansancio físico, sino que los cargadores se exponen a absorber las malas energías que transmiten los cuerpos en descomposición, lo que pueden producirles una enfermedad que se evidencia con dolor de cabeza y nauseas. De allí que los cargadores de ataúd del difunto requieren mayores atenciones, pues su pronta recuperación dependerá de la cantidad de comida y bebida que ingieran, mientras abunde mejor. 


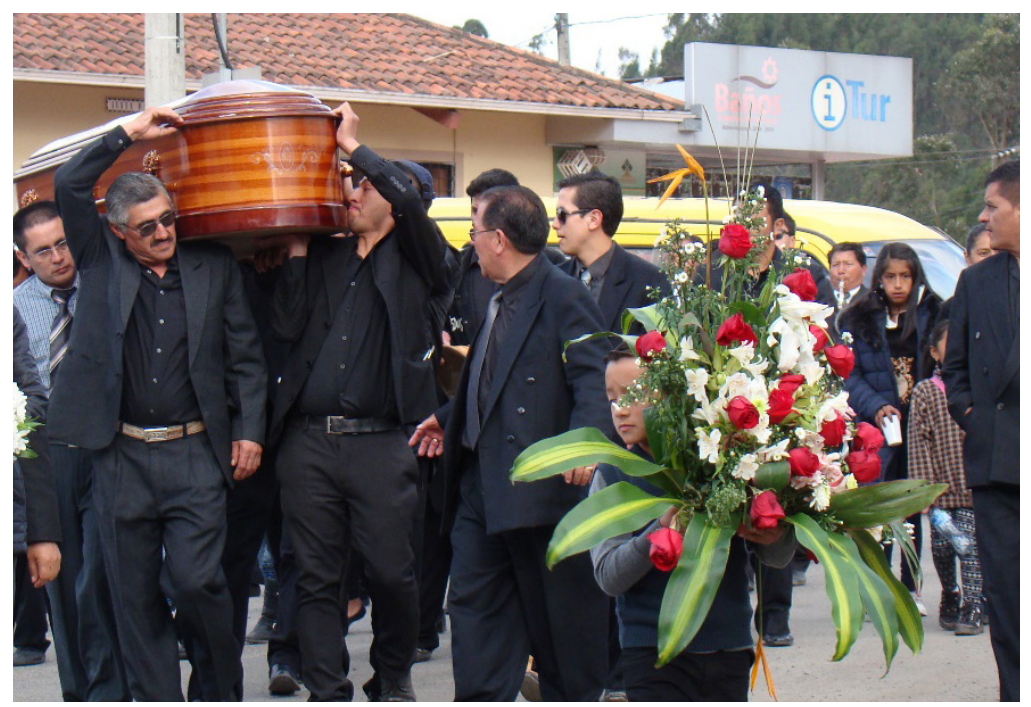

Figura 4. Cargadores del ataúd, de camino al cementerio

La comensalidad al comer y beber juntos después del entierro, es claramente un rito de agregación por el que los participantes retornan a la vida normal y los deudos asumen su nueva posición social: viudo (a), huéfano (a). Sera y Fernández señalan que "la comida ceremonial es un hecho de la vida colectiva, cosa normal cuando se considera que es la colectividad la que reconoce oficialmente los estados de transición por las cuales pasa cada individuo, el bautismo, matrimonio, muerte..." (1981, p. 49).

En este sentido, la comensalidad es un vector de diferenciación, pero también de inclusión que articula la sociabilidad entre los más cercanos con relaciones de distancia sociológica (Ver Salhins, 1977b). La comensalidad al comer y beber juntos es precisamente la que contribuye de manera fundamental a construir lo social. La comida constituye el soporte emocional y de reciprocidad que favorece a que las relaciones sociales no se extingan. 


\section{Conclusiones}

Reflexionar sobre la comensalidad al comer y beber juntos en el contexto fúnebre rural de Cuenca, sin duda conduce a una comprensión más amplia de las relaciones que una población teje con su espacio geográfico, social $\mathrm{y}$ económico, $\mathrm{y}$ de las concepciones que se generan en torno a la vida y a la muerte. Para estas poblaciones, y para gran parte de las poblaciones andinas del Ecuador, el intercambio de dones de comida y de bebida en el contexto fúnebre propicia sentidos de parentesco entre los participantes y origina una cadena de compromisos adquiridos que se sostiene en códigos morales. El cumplimiento exitoso de estos define la continuidad social del grupo.

La comida común consagra y fortifica los lazos creados por las relaciones familiares y vecinales, refuerza la solidaridad, amistad y convivencia. La bebida, por su parte, da lugar a un ambiente festivo y rompe con esquema rígido del ritual. Permite superar el "yo calculador e individualista", posibilita la comunicación entre los participantes y propicia un ambiente comunitario en el funeral. Estos grupos casi comunitarios como los que tienen lugar en los funerales domiciliares de los núcleos rurales se diferencian es la familia quien asume la posición fundamental y quien va a dar lugar a una forma de convivencia extra-familiar.

En este sentido, la comensalidad en la práctica fúnebre, como rito de agregación, ayuda a los participantes a asumir la muerte, incorpora al difunto al mundo de los muertos y permite el retorno del curso normal de la vida. Pese a las trasformaciones de los cultos funerarios en el tiempo, la intimidad del hogar permite que varios elementos culturales se enlacen a partir del compartir de la comida y la bebida y generen complejas formas de comprender y vivir la muerte sustentada en la deuda y la reciprocidad. Se trata de un micro-universo cultural que privilegia la organización social como valor fundamental de la vida. 


\section{Referencias bibliográficas}

Appadurai, A. (1986). "Introduction: commodities and the politics of value". En A. Appadurai (comp), The social life of things. Commodities in cultural perspective. Cambridge: Cambridge University Press.

Arriaga, P. J. (1621). La Extirpación de la Idolatría en el Perú. Colección de libros y documentos referentes a la Historia del Perú. (1920). Lima.

Brownrigg, L. (1971). El papel de los ritos de pasaje en la integración social de los cañaris quichuas del austro ecuatoriano. Revista de Antropología. N. ${ }^{\circ} 3$ (pp. 203-214). Cuenca: Casa de la Cultura Ecuatoriana.

Brownrigg, L. (1989). Un juego de pishca al huairu en Quingeo, Azuay. Revista de Antropología. N. ${ }^{\circ} 10$ (pp. 9-38). Cuenca: Casa de la Cultura Ecuatoriana.

Cachiguango, L. (2001). ¡Wantiay...! El ritual funerario andino de adultos en Otavalo, Ecuador. Chungara Revista de Antropología Chilena. 33 (2). Universidad de Tarapacá. Edición digital: https://dx.doi.org/10.4067/S0717-73562001000200003.

Carsten, J. (1989). "Cooking money: gender and the symbolic transformation of means of exchange in a Malay fishing community", en J. Parry \& M. Bloch (comp.) Money and the morality of exchange. Cambridge: Cambridge University Press.

Contreras, J. (1993). Alimentación y cultura: Reflexiones desde la Antropología.

Durkheim, E. (1990d) [1897], Le suicide. Étude de sociologie, 5a ed., París: PuF [edición original: París: Alcan]

Duviols, P. (1973) "Huari y Llacuz: agricultores y pastores. Un dualismo pre-hispánico de oposición y complementariedad”. Revista del Museo Nacional 39: 153-191. 
Ferraro, E. (2004). Reciprocidad, don y deuda. Quito: Ediciones AbyaYala.

Fischler C. (1979) Gastronomie et gastroanomie. Sagesse du corps et crise bioculturelle de l'alimentation moderne, Communications 31, 189-210.

Geertz, C (1997), La interpretación de las culturas. Barcelona: Gedisa.

Goody, J. 1982. Cooking, Cuisine and Class.Cambridge: Cambridge University Press.

Guber, R. (2001). La etnografía. Método, campo y reflexividad. Buenos Aires: Editorial Norma.

Haaland, R. 2007. Porridge and Pot, Bread and Oven: FoodWays and Symbolism in Africaand the Near East fromNeolithic to the Present.Cambridge Archaeological Journal 17, 16682.

Hartmann, R. y Oberem, U. (1984). "Aportes al Juego del Huairu”, Revista de Antropología (pp. 67-101), Cuenca: Casa de la Cultura Ecuatoriana (8).

Hertz, R. (1990 [1907] La muerte. La mano derecha. México D.F.: Alianza Editorial Mexicana.

Karsten, R. (1930). Ceremonial Games of the South American Indians. Helsingfors: Societas Scientiarum

Malinowski, B. (1994). Magia, Ciencia y Religión. Buenos Aires: Planeta.

Mauss, Marcel (1979) [1950], "Ensayo sobre los dones. Motivo y forma del cambio en las sociedades primitivas", en Sociología y Antropología (pp. 155-263). Madrid: Tecnos.

Mead, Margaret. 1951. El alimento y la familia. Buenos Aires: Editorial Sudamericana

Mintz, S. (2003). Sabor a comida, sabor a libertad. Incursiones en la comida, la cultura y el pasado. México: Ediciones de la Reina Roja. 
Restrepo, E. (2018). Etnografía. Alcances, técnicas y éticas. Lima: Universidad Nacional Mayor San Marcos.

Rivet, P. (1910). "Costumbres funerarias de los indios del Ecuador (Provincia del Azuay)", Pedro Saad Herrería (comp.), Ecuador en los ojos de afuera, 2002. Tomo 12. (pp. 713178). Ecuador: Campaña Nacional Eugenio Espejo por el libro y la lectura.

Sahlins, M. (1997b). Economía de la edad de piedra. Madrid: Ediciones Akal.

Sera, A y Fernández, A. (1981). Salud e Higiene mental en un medio rural de la Sierra Morena cordobesa: Conquista. Zaragoza: Universidad de Zaragoza.

Simmel, G. 1986. El individuo y la libertad. Barcelona: Península Thomas, V. (1993). Antropología de la muerte. México D.F.: F.C.M

Valcárcel, L. (1980) “La religión Incaica”. Historia del Perú. Tomo 3 (pp. 75-202). Lima: Mejía Baca.

Van Gennep. A. (2008) Los ritos de paso. Madrid: Alianza Editorial.

Weismantel, Mary (1994). Alimentación, género y pobreza en los andes ecuatorianos. Quito: Ediciones Abya-Yala. 